\title{
THE RELATIONSHIP BETWEEN COPING RESPONSES AND QUALITY OF LIFE AMONG INDIAN ELDERLY POPULATION
}

KEY WORDS: Coping, QOL, elderly, COVID

\section{Pristina \\ Rosalyn* \\ Neha Parashar}

Postgraduate student, Department of Counselling Psychology, Montfort College, Bangalore. *Corresponding Author

Research Supervisor, Montfort College, Bangalore.

Old age is regarded as a time period when individuals experience change in many aspects of their lives. While being presented with various challenges over time, their resources like social support, physical and mental health, financial income, etc also tend to decline, thus leaving them at a loss of resources that are actually necessary to help them cope with these challenges. Most studies on elderly population have suggested these factors have an impact on their Quality of Life. The onset of the COVID pandemic (which was deemed health-threatening, especially for older people in comparison to adults of other age groups) and lockdown implied further complications for their health, mental well being and their daily functioning too. However, despite the absence of external sources of support, the presence of internal sources like coping could act as a protective factor in face of adversity, and have a positive influence on their Quality of Life.The aim of this research is to study the coping responses of elderly Indian population during the lockdown period of COVID pandemic, and its effect on their Quality of Life.

\section{INTRODUCTION:}

The onset of COVID and its effects on people was studied by researchers all over the world. The pandemic and lockdown has inflicted and continues to inflict, varying challenges to people worldwide - especially for the elderly population. In addition to the pre-existing conditions in older adults that occur with aging; the onset of Covid has rendered the Elderly Population even more helpless, for they are considered to be more vulnerable at the risk of contracting COVID. Lockdown and self isolation were officially imposed as a solution to prevent spread, however there is also evidence of isolation affecting the mental health of older adults.

The WHO recognises individuals of 60 years and above, as older adults, and the population of those above 60 years of age can be collectively termed as elderly population. Aging is accompanied by profound changes in physical, psychological and social aspects of their lives (such as retirement, onset of diseases, cognitive impairment, loss of autonomy, death of loved ones, etc), which are accompanied by increase in levels of stress and can affect their Quality of Life. Furthermore, these changes cause their internal (health, finance) and external (decreased social support, retirement) resource systems to decrease, leaving them with very limited resources to work through the challenges in everyday life (González \& Padilla, 2006; Sachs-Ericsson et al.,2014).

Quality of Life (QOL) is defined as a multidimensional concept with both objective and subjective factors that refer to general satisfaction with life or its components. Some of the factors that influence one's quality of life are emotional, material, and physical well-being; engagement in interpersonal relations; and participation in society (Lawton, 1991; Bowling et al., 2002). In line with this, while physical health, decreased stress and involvement in social activities has been correlated with higher QOL in older adults; on the other end, functional impairment, chronic diseases, and mortality are associated with depressive symptoms (Schoevers et al., 2000; Nilsson et al., 2011; Djukanovic et al., 2015). Loneliness is another important factor which is identified to be closely associated with depressive symptoms (Barg et al., 2006; Cacioppo et al., 2006; Hawkley and Cacioppo, 2010). A study by Cacioppo et al. (2010) has shown loneliness to be a significant predictor of increase in depressive symptomatology at least 1 year later.

While it has been studied that social participation with support systems alleviates the impact of functional limitation on elderly (Netuveli \& Blane, 2008), at times, physical disability can restrict the individuals from being able to engage in certain social or leisure activities, increasing isolation and reducing their quality of social support (Blazer, 1983). Eventually these factors (impaired social support and late-life depression) affect the quality of life of elderly population (Doraiswamy et al., 2002). The components for successful aging have been termed as freedom from chronic disease and disability, and high physical and mental functioning and social engagement (Berkman et al., 1993; Depp \& Jeste, 2006). This could explain why a number of studies that have been conducted on elderly population, have emphasized the importance of developing adequate coping strategies to help minimize the emotional consequences of stressful situations and adapt to them.

However, although the period of old age of an individual's life is often viewed as a time of frailty accompanied by disability, declining sensory and motor functions, and increased physical and mental limitations, there exist a few studies which show older adults actually experiencing high wellbeing and quality of life, and consider themselves to be aging successfully despite the onset of chronic conditions (Kinsel, 2005; Nygren et al, 2005; Bowling \& Iliffe, 201 1; Jeste, Savla, \& Thompson et al., 2013). Psychologically, old age can be considered as a time of resilience and fortitude (Hamarat et al., 2002) and they are studied to have the same or greater capacity for resilience than those who are younger (Nygren et al., 2005; Netuveli \& Blane 2008; Gooding, Hurst, Johnson, \& Tarrier, 2012).

When bringing the onset of COVID into picture too, older adults were found to have less negative affect and more positive affect and reported positive daily events more often than the young and middle-aged groups, despite similar levels of perceived stress (Klaiber, Wen, DeLongis , \& Sin, 2020). A survey was published in August 2020 by Centers for Disease Control and Prevention (CDC), where elderly participants aged 65 years or older reported significantly lower percentages of anxiety disorder, depressive disorder, or trauma- or stress-related disorder than participants in younger age groups (Czeisler et al., 2020). A comparative study indicated that older age, when compared with younger age, was associated with lower rates of anxiety, depression, and PTSD (González-Sanguino et al. 2020). Although loneliness was reported to have increased after the pandemic, mental health levels of older adults remained unchanged before and after the start of the pandemic (van Tilburg et al., 2020). One important protective factor against the stressors could be the employment of coping strategies. 
Coping has been defined as a category of adaptation that is employed by individuals, especially under challenging circumstances (Costa, Somerfield, \& McCrae, 1996). Lazarus and Folkman $(1984$, pl41) defined the process of coping as cognitive and behavioral efforts undertaken by an individual in order to deal with demands that are especially challenging and sometimes even exceed their capacities and/or resources to deal with the situation. The goal of coping strategies is to compensate for the challenges, alleviate stressful situations, either by reformulation of objectives, or adjustment to a new and positively assessed situation (Gamrowska \& Steuden, 2014)

Coping strategies were categorized as problem-focused and emotion-focused by Lazarus and Folkman (1984). Problem focused strategies are aimed at modifying and/or dealing with the problematic situation and its impact; and emotion focused strategies are aimed at individual's self-regulation and thereby minimizing, preventing or reducing the emotional consequences caused by stressful situations (Schoenmakers et al., 2015). Coping strategies like acceptance, emotional social support, positive reframing, humour, and engagement in religious activities are categorised as emotion focused, while active coping, planning and instrumental support are considered to be problem-focused. Problem-focused coping strategies have been employed frequently in situations where the problem/stressor can be controlled, and they help improve psychological well-being. Emotion-focused coping strategies are suitable with problem situations that are inalterable, where the stressor cannot be controlled (Folkman, 1984; Park et al., 2004).

A second order dimension of coping strategies was established as adaptive vs maladaptive coping strategies, where venting, denial, behavioral disengagement, selfblame, self-distraction and substance use were categorised as maladaptive coping strategies; while active coping, positive reframing, acceptance, planning, seeking social support, using instrumental and emotional support, religion, and humor were categorised as adaptive coping strategies (Meyer, 2001). Maladaptive strategies are found to be associated with mental health problems and perceived stress, while adaptive strategies are associated with psychological well being (Meyer, 2001; Garcia et al., 2018). Despite the presence of functional limitations, adaptive coping styles in older adults is studied to be one of the protective factors, as well as a characteristic of resilient outcomes relative to their QOL (Zoe Hildon et al. 2010).

Endler and Parker (1990) suggested adding a third set of strategies, namely avoidant coping strategies, where the individual avoids stressful situations by seeking the company of others, engaging in different activities, etc. Stating that the distinction between problem-focused and emotion-focused coping strategies is insufficient, Carver et al (1989) identified 13 dimensions of coping. Five of them were interpreted as sub-dimensions of problem-focused coping (active coping, planning, suppression of competing activities, restraint coping, seeking social support for instrumental reasons), another five were categorised as sub-dimensions of emotionfocused coping (seeking social support for emotional reasons, positive reinterpretation and growth, acceptance, denial, turning to religion); and the remaining three were classified "less useful" strategies (venting of emotions, and mental and behavioral disengagement).

Coping strategies have been found to function as the mediator between stressors and their impact on QOL in the elderly, (León-Navarrete et al., 2017). This study aims to understand the influence of coping strategies on the quality of life among the Indian elderly population.

\section{Research problem:}

Do coping responses have an impact on the quality of life in elderly adults?

\section{Objectives:}

To identify the various coping styles employed by elderly adults, and to study the relationship between coping responses and Quality of Life in elderly adults.

\section{Hypothesis}

There would be no significant relationship between any of the coping styles and quality of life in elderly adults.

\section{Methodology:}

Data was collected using surveys via online questionnaires. Purposive sampling was the sampling method employed in the study. The link to the online questionnaire was circulated with elderly adults of ages 60 and above. The questionnaires included demographic details, WHOQOL-OLD and Brief RCOPE. Consent was obtained from the participants who were willing to participate in the study, and instructions provided. They were informed that there are no right or wrong answers and asked not to ponder on a question for too long, and respond with the answer that comes immediately to their mind. The sample of the study comprised 82 older adults of the age group 60 and above.

\section{RESULTS:}

Data was tested for correlation using parametric measures namely Kolmogorov-Smirnova and Shapiro-Wilk tests of normality. However, the significance level was 0.000 and thus, data was not normally distributed. Hence, correlation was measured using a non parametric measure-Spearman's rho.

Table 1 indicating the mean and standard deviation values for coping methods, QOL and its facets.

\begin{tabular}{|l|l|l|}
\hline & Mean & Std deviation \\
\hline Self distraction & 5.82 & 1.649 \\
\hline Active Coping & 5.41 & 1.699 \\
\hline Denial & 3.39 & 1.654 \\
\hline Substance use & 2.50 & 1.399 \\
\hline Use of emotional support & 5.55 & 1.82 \\
\hline Use of instrumental support & 5.13 & 1.762 \\
\hline Behavioural disengagement & 3.63 & 1.674 \\
\hline Venting & 4.27 & 1.397 \\
\hline Positive reframing & 6.07 & 1.705 \\
\hline Planning & 5.00 & 1.918 \\
\hline Humour & 4.43 & 1.839 \\
\hline Acceptance & 6.61 & 1.368 \\
\hline Religion & 6.02 & 2.09 \\
\hline Self blame & 2.88 & 1.29 \\
\hline Sensory abilities & 7.26 & 3.25 \\
\hline Autonomy & 14.99 & 3.623 \\
\hline Past present future abilities & 15.10 & 3.157 \\
\hline Social participation & 14.95 & 3.413 \\
\hline Death and dying & 6.82 & 4.263 \\
\hline Intimacy & 15.35 & 3.588 \\
\hline WHOQOL-OLD Total & 67.21 & 11.197 \\
\hline
\end{tabular}

With the number of participants being 82 , mean values were calculated for the participants' responses on Coping and Quality of Life. The mean value of Quality of Life is 67.21, and it can be seen that the mean scores of facets Autonomy, Past Present Future (PPF) abilities, Social Participation and Intimacy are relatively higher in comparison with mean scores of Sensory abilities, and Death and Dying. Thus, the quality of life in elderly population can be impacted poorly by limited sensory functioning, and concerns about death and dying. However, their QOL is better in the facets of independence, satisfaction about achievements in the past and goals for future, participation in activities and ability to have intimate relationships.

From the mean values of coping responses, it can be seen that predominantly employed coping methods are adaptive strategies namely acceptance, positive reframing and religion; and the least employed coping methods are maladaptive strategies namely substance use, self blame and denial. 
Table 2 indicating the correlation coefficients between coping methods, QOL and its facets.

\begin{tabular}{|l|l|l|l|l|l|l|l|}
\hline & $\begin{array}{l}\text { Sensory } \\
\text { abilities }\end{array}$ & Autonomy & $\begin{array}{l}\text { Past present future } \\
\text { abilities }\end{array}$ & $\begin{array}{l}\text { Social } \\
\text { participation }\end{array}$ & $\begin{array}{l}\text { Death and } \\
\text { dying }\end{array}$ & Intimacy & WHOQOL total \\
\hline Self distraction & 0.087 & $0.330^{* *}$ & $0.357^{* *}$ & $0.347^{* *}$ & -0.018 & $0.243^{*}$ & $0.389^{* *}$ \\
\hline Active Coping & 0.084 & $0.454^{* *}$ & $0.385^{* *}$ & $0.357^{* *}$ & 0.090 & $0.269^{*}$ & $0.495^{* *}$ \\
\hline Denial & 0.111 & 0.038 & 0.174 & 0.013 & 0.016 & 0.051 & 0.093 \\
\hline Substance use & $0.366^{* *}$ & -0.106 & -0.117 & -0.082 & 0.212 & -0.190 & -0.071 \\
\hline Use of emotional support & -0.141 & $0.355^{* *}$ & $0.297^{* *}$ & $0.321^{* *}$ & -0.022 & $0.275^{*}$ & $0.418^{* *}$ \\
\hline Use of instrumental support & -0.088 & $0.228^{*}$ & 0.101 & 0.150 & 0.079 & 0.055 & $0.229^{*}$ \\
\hline Behavioural disengagement & 0.054 & 0.048 & -0.058 & -0.002 & 0.085 & -0.051 & 0.031 \\
\hline Venting & -0.079 & 0.195 & $0.252^{*}$ & 0.146 & 0.031 & 0.204 & $0.280^{*}$ \\
\hline Positive reframing & $-0.291^{* *}$ & $0.443^{* *}$ & $0.444^{* *}$ & $0.425^{* *}$ & $-0.293^{* *}$ & $0.435^{* *}$ & $0.454^{* *}$ \\
\hline Planning & -0.029 & $0.469^{* *}$ & $0.426^{* *}$ & $0.396^{* *}$ & 0.019 & $0.290^{* *}$ & $0.514^{* *}$ \\
\hline Humour & -0.014 & $0.310^{* *}$ & $0.248^{*}$ & 0.145 & -0.180 & $0.300^{* *}$ & $0.243^{*}$ \\
\hline Acceptance & $-0.272^{*}$ & $0.532^{* *}$ & $0.439^{* *}$ & $0.432^{* *}$ & -0.217 & $0.494^{* *}$ & $0.513^{* *}$ \\
\hline Religion & -0.167 & 0.166 & 0.184 & $0.233^{*}$ & -0.088 & 0.209 & $0.227^{*}$ \\
\hline Self blame & 0.127 & -0.105 & -0.159 & $-0.232^{*}$ & 0.139 & -0.085 & -0.106 \\
\hline
\end{tabular}

*-Correlation is significant at the 0.05 level (2-tailed)

**-Correlation is significant at the 0.01 level (2-tailed)

From the table, we can observe a positive correlation between WHOQOL total and the following coping styles: self distraction, active coping, use of emotional and instrumental support, venting, positive reframing, planning, humour, acceptance and religion. In simple terms, the more the usage of these coping strategies, the higher is their overall Quality of Life measured to be. Thus, a mixture of both problem focused and emotion focused strategies have been employed by the elderly, which collectively impact their Quality of Life.

The results of the present study indicates positive correlation between the coping styles of self-distraction, planning, active coping, humour, emotional support, acceptance and positive reframing, with QOL facets of Autonomy, Past Present Future abilities, Social participation and Intimacy. Thus, employing adaptive coping strategies such as distracting oneself from overwhelming and discouraging news, dealing with problem situation, making lighthearted humour, spending time with loved ones, accepting and making meaning out of struggle; can help in alleviating the effects of pandemic and other stressors, thereby increasing their QOL in the areas of independence, achievement in life, social participation and intimacy. Although self distraction had been categorised under maladaptive strategies previously, in view of the current pandemic, distracting oneself from ongoing lockdown situation and overwhelming information about COVID can be considered as an adaptive strategy.

Instrumental support is positively correlated with the facet of autonomy, which can be explained by the availability of instrumental support equipping the elderly with more resources to cope and experiencing greater independence. Religious coping consists of performing religious activities and providing a sense of connectivity with fellow believers in the community, which can explain the positive correlation between religious coping and social participation.

A positive association is found between QOL in sensory functioning and substance use, which can be explained as individuals with higher QOL having the option to cope using substances too. While those with lesser physical efficiency are mindful to not use substances for coping. There is a negative correlation between self blame and social participation, ie, the lesser the sense of being connected within their community, the more they may resort to the maladaptive strategy of blaming oneself. It can also take another pathway, where the employment of self blame could drive others away, thereby affecting their QOL with respect to social participation.

The facet Sensory Abilities is negatively correlated with acceptance and reframing. That is, decreased QOL due to physical limitations is associated with increasingly employing acceptance and positive reframing; which could be the strategies they try to cope with when experiencing physical limitations. The facet Death and Dying is negatively correlated with positive reframing. That is, the lower their $\mathrm{QOL}$ is due to worries regarding death, the more they try to cope with the help of positive reframing strategies.

\section{Implications:}

The results of this study can be applied to elderly population, where they can be supported by maximizing resources for coping in order to improve their Quality of Life during adverse situations.

\section{Limitations:}

The present study measures the relationship between coping and QOL, however the presence of other factors (such as resilience, psychological well being, etc.) could have an impact on either/both of the variables. The present data is not normally distributed which could pave way for error.

\section{Scope for future research:}

A similar study can be conducted on a bigger population. Additional variables such as stress, resilience, psychological well being, can be included in future studies to identify their relationship with QOL too.

\section{CONCLUSION:}

The coping methods predominantly employed by elderly Indian adults are adaptive strategies namely positive reframing, religion and acceptance (adaptive), and the least employed coping strategies are maladaptive strategies namely substance use, self blame and denial.

The relationship between QOL and coping methods can vary with each coping style. In the current study, the following coping strategies were found to have a positive correlation with Quality of Life in Elderly adults: (i)self-distraction from pandemic situation, (ii)active coping, (iii)use of environmental support and (iv)instrumental support, (v) venting (vi)positive reframing, (vii)planning, (viii)humour, (ix)acceptance and (x)religion.

Whereas, there was no correlation found between QOL and the rest of coping strategies namely (i)denial, (ii)substance use, (iii)behavioural disengagement and (iv)self blame, all of which are categorised under maladaptive strategies.

\section{REFERENCES}

[1] Barg,F.K. Huss-Ashmore, R. Wittink, M.N., Murray, G.F., Bogner, H.R. \& Gallo, J. J. (2006). "A mixed-methods approach to understanding loneliness and depression in older adults." J. Gerontol. B Psychol. Sci. Soc. Sci. 61,S329-S339.

[2] Berkman, L. F., Seeman, T.E., Albert, M., Blazer, D., Kahn, R., Mohs, R., Finch, C. Schneider, E., Cotman, C., McClearn, G., et al. (1993). High, usual and impaired functioning in community-dwelling older men and women: findings from the MacArthur Foundation Research Network on Successful Aging.J Clin Epidemiol.46(10):1129-40. 
[3] Blazer, D. G. (1983). "Impact of late-life depression on the social network." Am JPsychiatry. 140(2):162-6.

[4] Bowling, A., Banister, D., Sutton, S., Evans, O., \& Windsor, J. (2002). "A multidimensional model of the quality of life in older age." Aging Ment. Health, 6,355-371.

[5] Bowling, A. \& Iliffe, S. (2011). "Psychological approach to successful ageing predicts future quality of life in older adults." Health and Quality of Life Outcomes, 9(13), ISSN (online) 1477-7525.

[6] Cacioppo,J.T., Hughes, M. E.,Waite, L. J., Hawkley, L. C., \& Thisted, R. A. (2006) "Loneliness as a specific risk factor for depressive symptoms: cross-sectional and longitudinal analyses." Psychol. Aging 21, 140-151.

[7] Cacioppo, J. T., Hawkley, L. C., \& Thisted, R. A. (2010). "Perceived social isolation makes me sad: 5-year cross-lagged analyses of loneliness and depressive symptomatology in the chicago health, aging, and social relations study." Psychol.Aging 25,453-463.

[8] Carver, C.S. (1997). "You want to measure coping but your protocol's too long: Consider the Brief COPE." International Journal of Behavioral Medicine, 4, 92-100.

[9] Carver C., Scheier M., \&Weintraub K. (1989). "Assessing coping strategies: a theoretically based approach."J.Pers. Soc.Psychol.56 267-283.

[10] Costa, P. T., Jr., Somerfield, M. R., \& McCrae, R. R. (1996). "Personality and coping:A reconceptualization." In M.Zeidner \& N.S. Endler (Eds.), Handbook of coping:Theory, research, applications (pp. 44-61).John Wiley \& Sons.

[11] Czeisler, M.É., Lane, R. I., Petrosky, E., et al. (2020). "Mental Health, Substance Use, and Suicidal Ideation During the COVID-19 Pandemic - United States." MMWR Morb MortalWkly Rep 2020;69:1049-1057.

[12] Depp, C. A. \& Jeste, D. V. (2006). "Definitions and predictors of successful aging: a comprehensive review of larger quantitative studies." Am JGeriatr Psychiatry 2006; 14:6-20

[13] Djukanovic, I., Sorjonen, K., \& Petersona, U. (2015). "Association between depressive symptoms and age, sex, loneliness and treatment among older people in Sweden." Aging Ment. Health, 19,560- 568.

[14] Doraiswamy, P. M., Khan, Z. M., Donahue, R. M., \& Richard, N. E. (2002). "The spectrum of quality-of-life impairments in recurrent geriatric depression." J Gerontol A Biol Sci Med Sci. 57(2):M134-7.

[15] Endler, N. S., \& Parker, J. D. (1990). "Multidimensional assessment of coping: a critical evaluation." J.Pers. Soc. Psychol.5,844-854

[16] García, F. E., Barraza-Peña, C. G., Wlodarczyk, A., Alvear-Carrasco, M., \& Reyes-Reyes, A. (2018). "Psychometric properties of the Brief-COPEfor the evaluation of coping strategies in the Chilean population." Psicologia: Reflexão e Crítica (2018) 31:22

[17] Gamrowska, A., \& Steuden, S. (2014). "Coping with the events of daily life and quality of life of the socially active elderly." Health Psychology Report, 2(2), 123-131.

[18] González, A., \& Padilla, A. (2006). "Quality of Life and Coping Strategies against Problems and Diseases in Mexican City Elderly Population." Universitas Psychologica, 5,501-509.

[19] González-Sanguino, C., Ausín, B., Castellanos, M. Á., Saiz, J., López-Gómez, A., Ugidos, C., \& Muñoz, M. (2020). "Mental health consequences during the initial stage of the 2020 Coronavirus pandemic (COVID-19) in Spain." Brain Behav Immun. 87:172-176

[20] Gooding, P. A., Hurst, A., Johnson, J., \& Tarrier, N. (2012). "Psychological resilience in young and older adults." Int J Geriatr Psychiatry. 27(3):262-70.

[21] Hamarat, E., Thompson, D., Aysan, F., Steele, D., Matheny, K., \& Simons, C. (2002)."Age differences in coping resources and satisfaction with life among middle-aged, young-old, and oldest-old adults." J Genet Psychol. 163(3):3607.

[22] Hildon, Z., Montgomery, S. M., Blane, D., Wiggins, R. D., \& Netuveli, G. (2010). "Examining resilience of quality of life in the face of health-related and psychosocial adversity at older ages: what is "right" about the way we age?" Gerontologist 50,36-47.

[23] Jeste, D.V., Savla, G.N. \& Thompson,W. K. et al. (2013). "Older age is associated with more successful aging: role of resilience and depression." Am J Psychiatry. 170(2): 188-196.

[24] Kinsel, B. (2005). "Resilience as Adaptation in Older Women." Journal of Women \& Aging.Volume 17,2005 - Issue 3

[25] Klaiber, P., Wen, J. H., DeLongis, A., \& Sin, N. L. (2021). "The Ups and Downs of Daily Life During COVID-19: Age Differences in Affect, Stress, and Positive Events."J Gerontol B Psychol Sci Soc Sci.76(2):e30-e37.

[26] Lawton, M. P. (1991). "A multidimensional view of quality of life in frail elders." The Concept and Measurement of Quality of Life in the Frail Elderly, (p3-27). San Diego, CA: Academic Press.

[27] Lazarus, R. \& Folkman, S. (1984). "Stress Appraisal and Coping." Springer, NewYork, pl41.

[28] León-Navarrete, M. M., Flores-Villavicencio, M. E., Mendoza-Ruvalcaba, N. Colunga-Rodríguez, C., Salazar-Garza, M. L., Sarabia-López, L. E., \& AlbánPérez, G. G. (2017). "Coping Strategies and Quality of Life in Elderly Population." Open Journal of Social Sciences Vol.5 No. 10,2017.

[29] Meyer, B. (2001). "Coping with severe mental illness: Relations of the Brief COPE with symptoms, functioning, and well-being." Journal of Psychopathology and Behavioral Assessment, 23(4), 265-277.

[30] Netuveli, G., \& Blane, D. (2008). "Quality of life in older ages: a review." British Medical Bulletin (Jan 2008). Retrieved from link https://academic.oup.com/ bmb/article/85/1/113/291398

[31] Nilsson, G., Ohrvik, J., Lonnberg, I., \& Hedberg, P. (2011). "Low Psychological GeneralWell-Being (PGWB) is associated with deteriorated 10-year survival in men but not in women among the elderly." Arch. Gerontol. Geriatr. 52, 167-171.

[32] Nygren, B., Alex, L., Jonsen, E., Gustafson, Y., Norberg, A., \& Lundman, B. (2005). "Resilience, sense of coherence, purpose in life and self transcendence in relation to perceived physical and mental health among the oldest old." Aging \& Mental Health, 9,354-362

[33] Park, C.L., Armeli, S., \& Tennen, H. (2004)."Appraisal-coping goodness of fit:A daily internet study." Personality and Social Psychology Bulletin, 30, 558-569.

[34] Sachs-Ericsson, N., Kendall-Tacket, K. A., Sheffler, J., Arce, D., Rushing, N. C., \& Cosentino, E. (2014). "The influence of prior rape on the psychological and physical health functioning of older adults". Aging Mental Health 18,717-730.

[35] Schoevers, R. A., Beekman, A. T., van Tillburg, W., Deeg, D. J., Jonker, C.,
Geerlings, M. I., et al. (2000). "Association of depression and gender with mortality in old age." Results from the Amsterdam Study of the Elderly (AMSTEL). Br.J.Psychiatry 177,336-342.

[36] Schoenmakers, E. C., van Tilburg, T. G., \& Fokkema, T. (2015). "Problemfocused and emotion-focused coping options and loneliness: how are they related?" Eur.J.Ageing 12, 153-161.

[37] van Tilburg, T. G., Steinmetz, S., Stolte, E., van der Roest, H., \& de Vries, D. H. (2020). "Loneliness and Mental Health During the COVID-19 Pandemic: A Study Among Dutch Older Adults."J Gerontol B Psychol Sci Soc Sci.

[38] World Health Organization. (2006). "WHOQOL-OLD Manual." European Office (Copenhagen). 